\title{
An optical sensor for mercury ion based on the fluorescence quenching of tetra( $p$-dimethylaminophenyl)porphyrin
}

\author{
Yu Yang ${ }^{\mathrm{a}, \mathrm{b}}$, Jianhui Jiang ${ }^{\mathrm{b}}$, Guoli Shen ${ }^{\mathrm{b}}$, Ruqin Yu ${ }^{\mathrm{b}, *}$ \\ a State Key Laboratory of Environmental Chemistry and Ecotoxicology, Research Center for Eco-Environmental Sciences, Chinese Academy of Sciences, Beijing 100085, PR China \\ ${ }^{\mathrm{b}}$ State Key Laboratory of Chemo/Biosensing and Chemometrics, College of Chemistry and Chemical Engineering, Hunan University, Changsha 410082, PR China
}

\section{A R T I C L E I N F O}

\section{Article history:}

Received 24 November 2008

Received in revised form 14 January 2009

Accepted 16 January 2009

Available online 23 January 2009

\section{Keywords:}

Optical sensor

Porphyrin

Mercury ion

Fluorescence

\begin{abstract}
A B S T R A C T
An optical sensor for mercury ion $\left(\mathrm{Hg}^{2+}\right)$, based on quenching the fluorescence of the sensing reagent porphyrin immobilized in plasticized poly(vinyl chloride) (PVC) membrane, has been developed. The responses to mercury ion were compared for the sensors modified with three porphyrin compounds including 5,10,15,20-tetraphenylporphyrin (TPP), tetra(p-dimethylaminophenyl)porphyrin (TDMAPP) and tetra(N-phenylpyrazole) porphyrin (TPPP). Among them, TDMAPP showed the most remarkable response to $\mathrm{Hg}^{2+}$. The drastic decrease of the TDMAPP fluorescence intensity was attributed to the formation of a complex between TDMAPP and $\mathrm{Hg}^{2+}$, which has been utilized as the fabrication basis of $\mathrm{a} \mathrm{Hg}^{2+}$-sensitive fluorescence sensor. The analytical performance characteristics of the TDMAPP modified sensor was investigated. The response mechanism, especially involving the response difference of three porphyrin compounds, was discussed in detail. The sensor can be applied to the quantification of $\mathrm{Hg}^{2+}$ with a linear range covering from $4.0 \times 10^{-8} \mathrm{~mol} \mathrm{~L}^{-1}$ to $4.0 \times 10^{-6} \mathrm{~mol} \mathrm{~L}^{-1}$. The limit of detection was $8.0 \times 10^{-9} \mathrm{~mol} \mathrm{~L}^{-1}$. The sensor exhibited excellent reproducibility, reversibility and selectivity. Also, the TDMAPP-based sensor was successfully used for the determination of $\mathrm{Hg}^{2+}$ in environmental water samples.
\end{abstract}

(C) 2009 Elsevier B.V. All rights reserved.

\section{Introduction}

Chemical sensor technology can provide low-cost devices that can be tuned to a wide field of application by coating mass-sensitive or optical transducers with a chemically sensitive layer [1]. The detection of molecular species by fluorescent sensing is of current interest [2]. Optical sensor based on fluorescent probe can be designed according to two guiding principles: (i) the absorption and emission features of the fluorophore are directly affected by the close interaction with the analyte, and/or (ii) the transformation of the photophysical properties resulted from the conformational changes of the sensor that are susceptible to the interaction with the analyte. In fact, much research work has been performed to develop fluorescent sensors for the detection of transition and heavy metal ions [3-6], which offer distinct advantages in terms of sensitivity, selectivity and response time. Also, the theoretical basis of such optical membranes based on plasticized PVC has been well established [7-9]. The porphyrins are a class of naturally occurring macrocyclic compounds, which play a very important role in the metabolism of living organisms. They have been extensively studied due to their biological importance as well as analytical applications

\footnotetext{
* Corresponding author. Fax: +86 7318822782.

E-mail addresses: yuyang@rcees.ac.cn (Y. Yang), rqyu@hnu.cn (R. Yu).
}

[10]. Particular attention has been given to porphyrins as highly sensitive chromogenic reagents for spectrophotometric determination of several metal ions [11].

Heavy metals, one of the most hazardous classes of pollutants in water sources due to their nonbiodegradability, have caused widespread water endangerment, contamination of fish, and serious health problems [12]. Mercury is one of the most well known toxic metals. Its toxicity is attributed to its harmful effects on the central nervous system disturbing haemin synthesis as well as causing neuropsychiatric disorders [13]. The cases in Minamata Bay in Japan in 1953 [14] were particularly disastrous. Mercury is usually present at low concentrations in environmental samples as inorganic, free or complexed with inorganic and organic ligands or as organomercury compounds. Therefore, determination of trace amounts of mercury in environmental samples is of great interest due to increasing public concern about environmental pollution and their high toxicity and accumulative and persistent character in the environment and living organisms. In recent years, several fluorescent sensors have been developed for the determination of $\mathrm{Hg}^{2+}$ [15-17]. Shamsipur et al. [18] have prepared a $\mathrm{Hg}^{2+}$ fluorescence sensor by incorporating 1-(dansylamidopropyl)-1-aza-4,10-dithia7-oxacyclododecane as a neutral $\mathrm{Hg}^{2+}$-selective fluoroionophore in the plasticized PVC membrane containing potassium tetrakis $(p-$ chlorophenyl) borate as a liphophilic anionic additive. At a pH 3.3, the proposed sensor displayed a calibration curve over a wide 
concentration range of $1.0 \times 10^{-4}-5.0 \times 10^{-12} \mathrm{~mol} \mathrm{~L}^{-1}$. He et al. [19] have developed a fluorescent sensor for $\mathrm{Hg}^{2+}$ using $5,10,15-$ tris(pentafluorophenyl)corrole as fluorophore. The sensor showed a linear response towards $\mathrm{Hg}^{2+}$ in the concentration range from $1.2 \times 10^{-7} \mathrm{~mol} \mathrm{~L}^{-1}$ to $1.0 \times 10^{-4} \mathrm{~mol} \mathrm{~L}^{-1}$. In a word, the response mechanisms of $\mathrm{Hg}^{2+}$ fluorescent sensors reported were all based on the strong fluorescence quenching of fluorescent material by $\mathrm{Hg}^{2+}$ ion. Moreover, these works all involved a very complex synthesis of fluorescent materials. As far as we know, some other analytical methods have been developed for the determination of mercury, such as electrochemical method [20-26], atomic absorption spectrometry [27-30] or cold-vapour inductively coupled plasma atomic emission [31], chromatographic determination [32-34], inductively coupled plasma-mass spectrometric analysis [35,36] or electrospray ionization mass spectrometry [37], room temperature phosphorimetry [38]. Although these methods are accurate, most require a tedious sample pre-treatment, sophisticated performance and/or expensive equipment. Therefore, a simple, fast, selective and sensitive analytical method is needed to determine mercury.

In this paper, we tried to synthesize three lipophilic porphyrin compounds, 5,10,15,20-tetraphenylporphyrin (TPP), tetra( $p$-dimethylaminophenyl)porphyrin (TDMAPP) and tetra(Nphenylpyrazole) porphyrin (TPPP) and respectively used them as sensing reagents in a hydrophobic membrane of PVC matrix. As a macrocylic compound, porphyrin exhibits strong fluorescence in visible region owing to the conjugated double bond system and the high mobility of its $\pi$-electron. After being immobilized in a plasticized PVC membrane, porphyrin can selectively extract $\mathrm{Hg}^{2+}$ from aqueous sample solution into organic membrane phase and form a metalloporphyrin compound, which results in a decrease of porphyrin fluorescence. This has been utilized as the preparation basis of $\mathrm{Hg}^{2+}$-sensitive fluorescent sensor. The recognition abilities for mercury ion of three porphyrin compounds were compared. The recognition difference of three porphyrin compounds was discussed in detail. TDMAPP showed preferable analytical performance characteristics for $\mathrm{Hg}^{2+}$ as compared to the two other porphyrin compounds. The analytical performance characteristics of the TDMAPP modified sensor was investigated. This sensor can be used for the determination of $\mathrm{Hg}^{2+}$ with a linear range covering from $4.0 \times 10^{-8} \mathrm{~mol} \mathrm{~L}^{-1}$ to $4.0 \times 10^{-6} \mathrm{~mol} \mathrm{~L}^{-1}$ with a detection limit of $8.0 \times 10^{-9} \mathrm{~mol} \mathrm{~L}^{-1}$. It showed excellent reproducibility, reversibility and selectivity. Also, the response mechanism of the sensing membrane was discussed.

\section{Experimental}

\subsection{Reagents}

High molecular weight poly(vinyl chloride) (PVC) (MW $\sim 300,000$ ), di-iso-octyl sebacate (DOS), tetrahydrofuran (THF) and mercuric nitrate $\left(\mathrm{Hg}\left(\mathrm{NO}_{3}\right)_{2} \cdot \mathrm{H}_{2} \mathrm{O}\right)$ were purchased from Shanghai Chemical Reagents (Shanghai, China). Three porphyrin compounds (Fig. 1), TPP [39], TDMAPP [40], TPPP [41] were synthesized according to the corresponding references and these products were verified by IR, MS, NMR and element analysis. All reagents were of analytical reagent grade. Doubly distilled water was used throughout.

\subsection{Apparatus}

All fluorescence measurements were performed with a Hitachi F-4500 fluorescence spectrometer. Excitation and emission slits were set at $5.0 \mathrm{~nm}$ and $10.0 \mathrm{~nm}$ respectively. All experiments were carried out at $20^{\circ} \mathrm{C}$. A homemade flow cell was used for the $\mathrm{Hg}^{2+}$ sensing measurements.
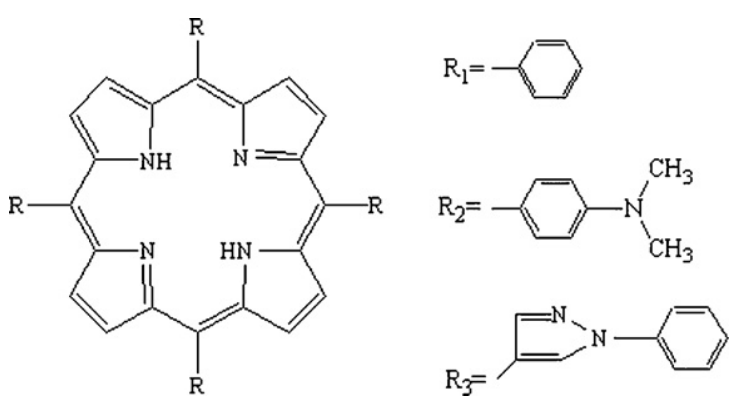

Fig. 1. The chemical structure of three porphyrin compounds: $1, T P P: R=R_{1} ; 2$, TDMAPP: $\mathrm{R}=\mathrm{R}_{2} ; 3$, TPPP: $\mathrm{R}=\mathrm{R}_{3}$.

\subsection{Membrane fabrication}

A circular $35 \mathrm{~mm}$ diameter quartz slide was first treated in dichlorodimethylsilane ( $10 \%$ solution in toluene) overnight at room temperature to make the surface hydrophobic and was washed sequentially with toluene, acetone and distilled water. Then, the quartz slide was fixed on the end of an aluminum alloy rod and then rotated at a frequency of $600 \mathrm{rpm}$. The sensing membrane solution was prepared by dissolving a mixture of $80 \mathrm{mg}$ of PVC, $160 \mathrm{mg}$ of DOS in $2.0 \mathrm{~mL} 5.0 \times 10^{-5} \mathrm{~mol} \mathrm{~L}^{-1}$ TDMAPP (or TPP or TPPP) THF solution. With a syringe, $0.2 \mathrm{~mL}$ of the membrane solution was injected on the center of the quartz slide. After spinning for $5.0 \mathrm{~s}$, a membrane of approximately $4.0 \mu \mathrm{m}$ thickness was then coated onto the quartz slide and dried in ambient air for $30 \mathrm{~min}$ prior to use [42].

\subsection{Measurement procedure}

The prepared PVC membrane was installed in a homemade flow cell with about $3.4 \mathrm{~mL}$ volume capacity. The cell was mounted into the fluorescence spectrometer in a fixed position to ensure the detection of fluorescence emission intensity without interference from the excitation light source [43]. The fluorescence intensity was measured at the maximal excitation wavelength of $438 \mathrm{~nm}$ and the maximal emission wavelength of $673 \mathrm{~nm}$. The $\mathrm{Hg}^{2+}$ solution was introduced into the flow cell by a peristaltic pump. After each measurement, the membrane was washed with $0.1 \mathrm{~mol} \mathrm{~L}^{-1} \mathrm{HCl}$ solution and then with the buffer solution until its fluorescence intensity reached the original blank value.

A standard stock solution of $2.0 \times 10^{-5} \mathrm{~mol} \mathrm{~L}^{-1} \mathrm{Hg}^{2+}$ was prepared. The working solutions were obtained by serial dilutions of this stock solution with $0.01 \mathrm{~mol} \mathrm{~L}^{-1}$ phosphate buffer solution $(\mathrm{pH}$ 8.0).

\section{Results and discussion}

\subsection{The fluorescence spectra of three porphyrin compounds and their responses to $\mathrm{Hg}^{2+}$}

The fluorescence spectra of three porphyrin compounds, as well as their responses to $\mathrm{Hg}^{2+}$, are shown in Fig. 2. Owing to the conjugated double bond system and the high mobility of their $\pi$-electrons, three porphyrin compounds all exhibited strong fluorescence emission. Noticeable decreases of fluorescence intensities were observed in the presence of $\mathrm{Hg}^{2+}$. It was noticed that the fluorescence intensity of TDMAPP was much stronger than those of TPP and TPPP. It seemed that the fluorescence quenching degree of TDMAPP was more remarkable than that of the two other porphyrin compounds. This can be explained by the fact that in comparison with TPP, the electron cloud density in porphin ring center of TDMAPP increased due to the introduction of electron-donating dimethylamino group into the phenyl group of TPP, which resulted 


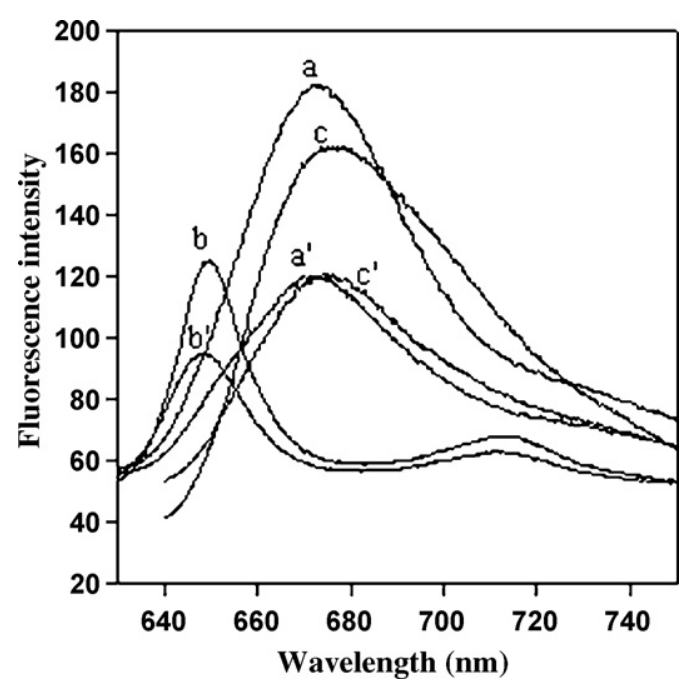

Fig. 2. The fluorescence spectra of three porphyrin compounds and their $\mathrm{Hg}^{2+} \mathrm{com}-$ plexes. $a$ and $a^{\prime}, b$ and $b^{\prime}, c$ and $c^{\prime}$, respectively represent the fluorescence spectra of TDMAPP, TPP, TPPP in the absence and presence of $\mathrm{Hg}^{2+}$. The concentration of $\mathrm{Hg}^{2+}$ was $4.0 \times 10^{-7} \mathrm{~mol} \mathrm{~L}^{-1}$.

in the enhancement of complexation ability of TDMAPP with $\mathrm{Hg}^{2+}$. While for TPPP, an electron-donating pyrazole group, was introduced in the position between phenyl group and porphin ring. The electron cloud density in pyrazole group was also distributed to the phenyl group except for porphin ring center of TPPP, which resulted in the thinner electron cloud density of porphin ring center of TPPP as compared to that of TDMAPP. So, the complexation ability with $\mathrm{Hg}^{2+}$ of TPPP was weaker than that of TDMAPP. As for TPP, the electron cloud density of porphin ring center was relatively the thinnest owing to the electron deficiency of coupled phenyl group. Accordingly, the complexation ability of TPP with $\mathrm{Hg}^{2+}$ was the weakest among the three porphyrin compounds.

For the fabrication of a sensor, sensitivity is the most important parameter. From the view of sensor sensitivity, the sensing membrane containing TDMAPP was chosen as an optimal optical sensor.

\subsection{Effect of $p H$ value}

The effect of $\mathrm{pH}$ value on the fluorescence intensity of TDMAPP sensing membrane was examined (Fig. 3). The blank fluorescence intensity of the sensing membrane itself was found to be depen-

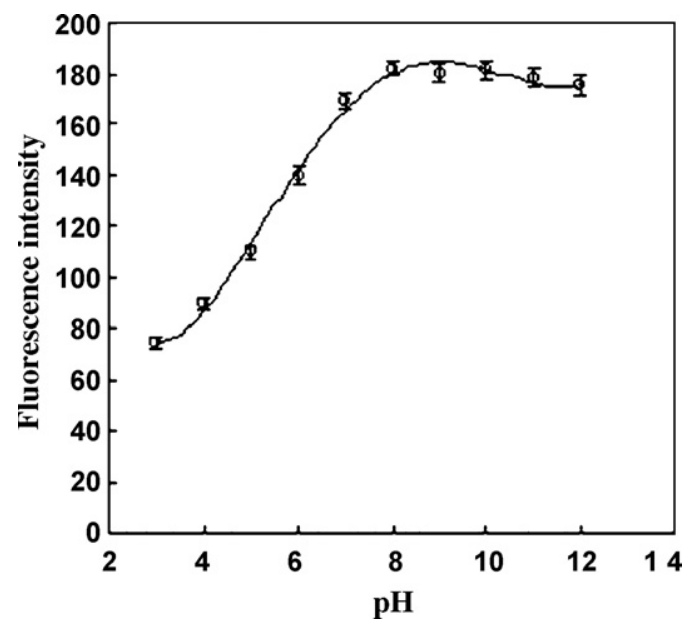

Fig. 3. The effect of $\mathrm{pH}$ value on the fluorescence intensity of sensing membrane.

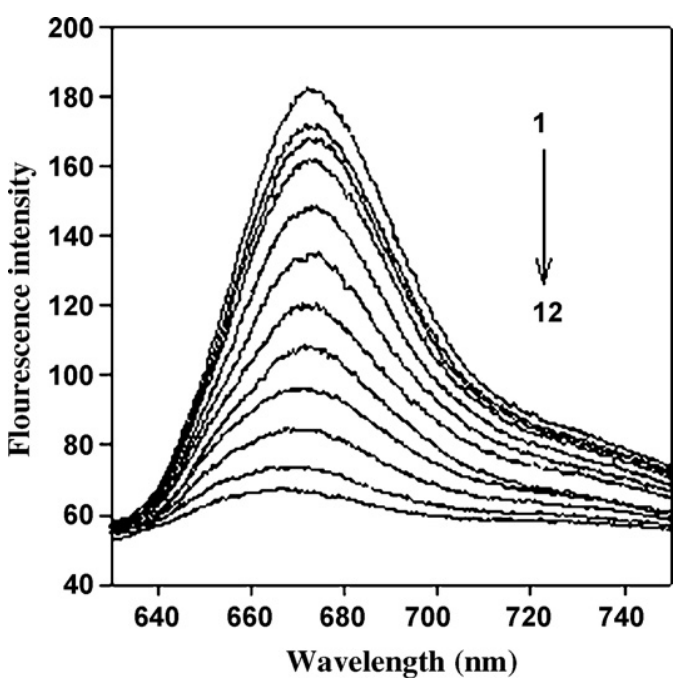

Fig. 4. The fluorescence emission spectra of the sensing membrane exposed to the solution containing different concentrations of $\mathrm{Hg}^{2+}: 1,0 ; 2,4.0 \times 10^{-8} \mathrm{~mol} \mathrm{~L}^{-1} ; 3$, $6.0 \times 10^{-8} \mathrm{~mol} \mathrm{~L}^{-1} ; 4,8.0 \times 10^{-8} \mathrm{~mol} \mathrm{~L}^{-1} ; 5,1.0 \times 10^{-7} \mathrm{~mol} \mathrm{~L}^{-1} ; 6,2.0 \times 10^{-7} \mathrm{~mol} \mathrm{~L}^{-1}$; 7, $\quad 4.0 \times 10^{-7} \mathrm{~mol} \mathrm{~L}^{-1} ; \quad 8, \quad 6.0 \times 10^{-7} \mathrm{~mol} \mathrm{~L}^{-1} ; \quad 9, \quad 8.0 \times 10^{-7} \mathrm{~mol} \mathrm{~L}^{-1} ; \quad 10$, $1.0 \times 10^{-6} \mathrm{~mol} \mathrm{~L}^{-1} ; 11,2.0 \times 10^{-6} \mathrm{~mol} \mathrm{~L}^{-1} ; 12,4.0 \times 10^{-6} \mathrm{~mol} \mathrm{~L}^{-1}$.

dent on the acidity of the soaking solution due to the existing of nitrogen atoms in TDMAPP molecule. It was found that the fluorescence intensity of sensing membrane enhanced with the increase of $\mathrm{pH}$ value till $\mathrm{pH}$ 8.0. No drastic changes of the fluorescence intensities were observed between 8.0 and 12.0. At high acidity, $\mathrm{H}^{+}$might be extracted into membrane phase and then complexed with the nitrogen atoms forming the protonated complex. Thus, the $\pi$-electron conjugated double bound system of TDMAPP would be destroyed, which resulted in the decrease of TDMAPP fluorescence intensity. In addition, at acidic condition, the coordination interaction between the protonated porphyrin and metal cation was very weak, and hence the fluorescence quenching efficiency would of course also decrease. Therefore, $\mathrm{pH} 8.0$ phosphate buffer solution $\left(0.01 \mathrm{~mol} \mathrm{~L}^{-1}\right)$ was selected as optimal experimental condition.

\subsection{Response to $\mathrm{Hg}^{2+}$ of sensing membrane}

Fig. 4 shows the fluorescence emission spectra of the TDMAPP sensing membrane exposed to the solutions containing different concentrations of $\mathrm{Hg}^{2+}$. Noticeable decrease of fluorescence emission intensity appeared in the presence of $\mathrm{Hg}^{2+}$, which was attributed to the formation of a complex between TDMAPP and $\mathrm{Hg}^{2+}$. Also, the fluorescence intensities of sensing membrane were gradually decreased with increasing $\mathrm{Hg}^{2+}$ concentrations, which has been utilized as the quantitative basis of the $\mathrm{Hg}^{2+}$ sensor.

\subsection{Theoretical principle of sensing membrane determination}

Suppose a complexation equilibrium between $\mathrm{Hg}^{2+}$ in the aqueous solution (aq) and TDMAPP in the plasticized PVC membrane phase (org) is established with formation of a complex with a complexing ration of $m: n$, the overall equilibrium can be represented as follows [7-9]:

$m \mathrm{~A}_{(\mathrm{aq})} \stackrel{k_{d}}{\Leftrightarrow} \mathrm{mA}_{(\text {org })}$

$m \mathrm{~A}_{(\text {org })}+n \mathrm{~B}_{(\text {org })} \stackrel{\beta}{\Leftrightarrow} \mathrm{A}_{m} \mathrm{~B}_{n(\text { org })}$

i.e.

$m \mathrm{~A}(\mathrm{aq})+n \mathrm{~B}($ org $) \stackrel{K}{\Leftrightarrow} \mathrm{A}_{m} \mathrm{~B}_{n}($ org $)$ 
Table 1

The information of other published methods for the determination of $\mathrm{Hg}^{2+}$.

\begin{tabular}{|c|c|c|}
\hline Analytical methods & Linear range $\left(\mathrm{mol} \mathrm{L}^{-1}\right)$ & The limit of detection $\left(\mathrm{mol} \mathrm{L}^{-1}\right)$ \\
\hline Electrochemical method & $2.0 \times 10^{-6}-1.0 \times 10^{-5}$ & $4.0 \times 10^{-7}$ \\
\hline Atomic absorption or emission spectrometry & $2.5 \times 10^{-8}-5.0 \times 10^{-6}$ & $2.0 \times 10^{-8}$ \\
\hline Chromatography & - & $2.5 \times 10^{-10}$ \\
\hline Mass spectrometry & - & $3.5 \times 10^{-12}$ \\
\hline Fluorimetry & $5.0 \times 10^{-12}-1.0 \times 10^{-4}$ & $8.0 \times 10^{-13}$ \\
\hline Room temperature phosphorimetry & $2.0 \times 10^{-8}-2.0 \times 10^{-7}$ & $2.3 \times 10^{-9}$ \\
\hline
\end{tabular}

where A represents $\mathrm{Hg}^{2+}$ and B denotes TDMAPP. When the difference between the activity and concentration is neglected for simplification, the corresponding equilibrium constant $K$ can be expressed by the law of mass action:

$K=k_{d} \beta=\frac{\left[\mathrm{A}_{m} \mathrm{~B}_{n}\right](\text { org })}{[\mathrm{A}]^{m}(\mathrm{aq})[\mathrm{B}]^{n}(\mathrm{org})}$

where $k_{d}$ is the distribution coefficient of $\mathrm{Hg}^{2+}$ between the organic and aqueous phases, $\beta$ is complex formation constant respectively, and $\left[A_{m} B_{n}\right],[A],[B]$ are the concentrations of respective species.

When the concentrations of $\mathrm{Hg}^{2+}$ and TDMAPP in membrane are low, the observed fluorescence intensity of the membrane is a sum of several contributions.

$F_{0}=K_{\mathrm{B}} C_{\mathrm{B}(\text { org })}$

$F=K_{\mathrm{A}}[\mathrm{A}]_{(\text {org })}+K_{\mathrm{B}}[\mathrm{B}]_{(\text {org })}+K_{\mathrm{A}_{m} \mathrm{~B}_{n}}\left[\mathrm{~A}_{m} \mathrm{~B}_{n}\right]_{(\text {org })}$

where $F_{0}$ is the fluorescence intensity of the sensing membrane when applied to blank solution, $F$ is the fluorescence intensity of the sensing membrane when applied to $\mathrm{Hg}^{2+}$ solution, $C_{\mathrm{B}(\text { org })}$ is the total concentration of TDMAPP in the membrane, and the $K_{i}$ values represent the individual proportion constants and include instrumental parameters as well as the quantum efficiency of the complex species.

To indicate the degree of association between TDMAPP and $\mathrm{Hg}^{2+}$ in the sensing membrane, a response parameter, $\alpha$, needs to be introduced and defined as follows:

$\alpha=\frac{C_{\mathrm{B}(\text { org })}-[\mathrm{B}]_{(\text {org })}}{C_{\mathrm{B}(\text { org })}}=\frac{n\left[\mathrm{~A}_{m} \mathrm{~B}_{n}\right]_{(\text {org })}}{C_{\mathrm{B}(\text { org })}}$

It can be derived from Eq. (5) to Eq. (7) that:

$\alpha=\frac{F-F_{0}}{F_{1}-F_{0}}$

where $F_{1}$ is the fluorescence intensity at membrane saturation.

Combining Eq. (4) and Eq. (7), one can obtain the following quantitative equation:

$\frac{\alpha^{n}}{1-\alpha}=\frac{1}{n K C_{\mathrm{B}}^{n-1}[\mathrm{~A}]^{m}}$

The relationship between $\alpha$ and [A] as expressed by Eq. (9) is the basis of the quantitative determination of $\mathrm{Hg}^{2+}$ using this sensing membrane.

\subsection{Response characteristics of the optical sensor}

The reproducibility and reversibility of the optical sensor in the determination of $\mathrm{Hg}^{2+}$ were evaluated by repetitively exposing the sensing membrane to $\mathrm{Hg}^{2+}$ solution of different concentrations, $0.1 \mathrm{~mol} \mathrm{~L}^{-1} \mathrm{HCl}$ solution and phosphate buffer solution $(\mathrm{pH} \mathrm{8.0)}$. The standard deviations of different sample solutions for three determinations were found to be $4.24\left(6.0 \times 10^{-8} \mathrm{~mol} \mathrm{~L}^{-1}\right), 3.78$ $\left(4.0 \times 10^{-7} \mathrm{~mol} \mathrm{~L}^{-1}\right)$, and $4.02\left(2.0 \times 10^{-6} \mathrm{~mol} \mathrm{~L}^{-1}\right)$. The standard deviation of blank solution was 3.63 for 12 determinations. The optical sensor was regenerated with $0.1 \mathrm{~mol} \mathrm{~L}^{-1} \mathrm{HCl}$ solution. The
$\mathrm{Hg}^{2+}$ complexed with TDMAPP could be eluted out of the sensing membrane quickly and completely, which demonstrated the excellent reproducibility and reversibility of the sensor.

For the sensing membrane in contact with a $6.0 \times 10^{-7} \mathrm{~mol} \mathrm{~L}^{-1}$ $\mathrm{Hg}^{2+}$ solution, the fluorescence intensity at $673 \mathrm{~nm}$ was recorded over a period of $8 \mathrm{~h}$. The fluorescence intensity was recorded with a 30 min interval, a standard deviation of 4.65 was obtained. After a series of 100 times measurements of $\mathrm{Hg}^{2+}$ solution, the fluorescence intensity value of the sensor did not change.

From Eq. (9), it can be seen that when the stoichiometric ratio of complex changes, the relative fluorescence intensity value $\alpha$ with the various concentration of $\mathrm{Hg}^{2+}$ exhibits different functional relationships. According to Eq. (9), the experimental data were fitted by altering the ratio of $m$ to $n$ and the equilibrium constant $K$. Fig. 5 shows the fitted curve for the determination of $\mathrm{Hg}^{2+}$. The curve of the $1: 1$ complex ratio and $K=2.5 \times 10^{6} \mathrm{~L} \mathrm{~mol}^{-1}$ was in agreement with the experimental data, which can serve as the calibration curve. A linear range for $\mathrm{Hg}^{2+}$ covered from $4.0 \times 10^{-8} \mathrm{~mol} \mathrm{~L}^{-1}$ to $4.0 \times 10^{-6} \mathrm{~mol} \mathrm{~L}^{-1}$. The limit of detection, defined according to $3 \sigma$ concept, was $8.0 \times 10^{-9} \mathrm{~mol} \mathrm{~L}^{-1}$. As a comparison, Table 1 gave the information of other published methods for the determination of $\mathrm{Hg}^{2+}$.

\subsection{Selectivity}

Some common ions including alkali, alkaline earth and heavy metal ions were chosen for the study on selectivity of the $\mathrm{Hg}^{2+}$ sensor. A foreign species was considered not to interfere with measurement if a relative error caused by it was less than $5 \%$ in the determination of $2.0 \times 10^{-7} \mathrm{~mol} \mathrm{~L}^{-1} \mathrm{Hg}^{2+}$. The results presented in

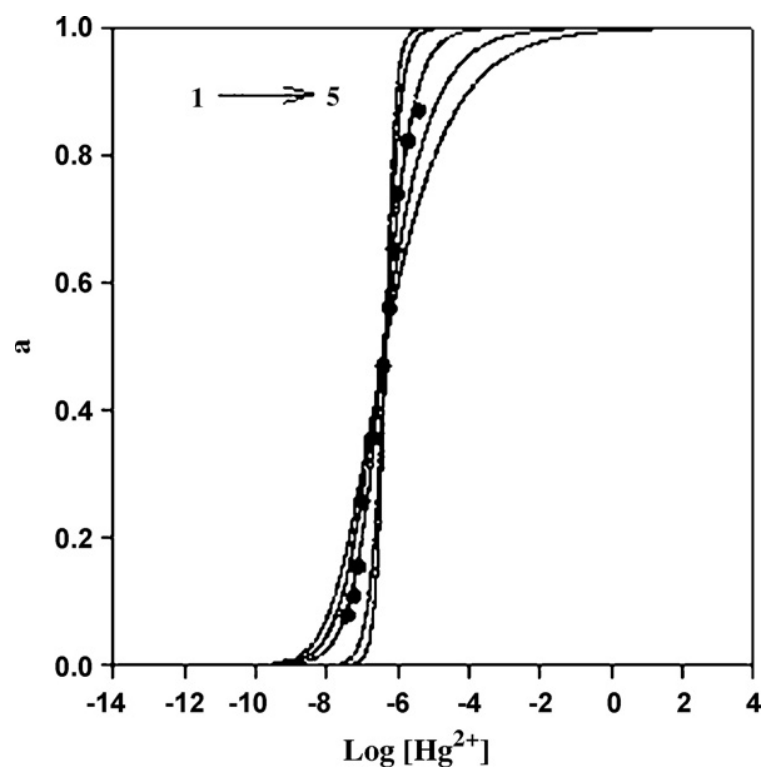

Fig. 5. Relative fluorescence intensity $\alpha$ as a function of $\log \left[\mathrm{Hg}^{2+}\right]$. The curve fitting the experimental data were calculated from Eq. (9). $1, m: n=3: 1$ and $K=1.0 \times 10^{19}$. $2, m: n=2: 1$ and $K=5.0 \times 10^{12} ; 3, m: n=1: 1$ and $K=2.5 \times 10^{6} ; 4, m: n=1: 2$ and $K=2.5 \times 10^{9} ; 5, m: n=1: 3$ and $K=3.0 \times 10^{12}$. 
Table 2

Interference of different species to the fluorescent determination of $\mathrm{Hg}^{2+}$ with the prepared sensor.

\begin{tabular}{|c|c|c|c|}
\hline Interferent & Concentration $^{\mathrm{a}}\left(\mathrm{mol} \mathrm{L}^{-1}\right)$ & Fluorescence intensity $\left(\Delta F=F_{i}-F_{i 0}\right)^{\mathrm{b}}$ & Relative error $(\%)\left(\left(\Delta F / F_{i 0}\right) \times 100\right)$ \\
\hline $\mathrm{Na}^{+}$ & $1.0 \times 10^{-1}$ & -2.1 & -1.6 \\
\hline $\mathrm{K}^{+}$ & $1.0 \times 10^{-1}$ & -2.6 & -1.9 \\
\hline $\mathrm{Ca}^{2+}$ & $1.0 \times 10^{-1}$ & 2.3 & 1.7 \\
\hline $\mathrm{Mg}^{2+}$ & $1.0 \times 10^{-1}$ & -3.0 & -2.2 \\
\hline $\mathrm{Ba}^{2+}$ & $1.0 \times 10^{-1}$ & 2.8 & 2.1 \\
\hline $\mathrm{Al}^{3+}$ & $1.0 \times 10^{-1}$ & 2.4 & 1.8 \\
\hline $\mathrm{Zn}^{2+}$ & $1.0 \times 10^{-5}$ & -3.4 & -2.5 \\
\hline $\mathrm{Fe}^{2+}$ & $1.0 \times 10^{-5}$ & -3.5 & -2.6 \\
\hline $\mathrm{Fe}^{3+}$ & $1.0 \times 10^{-5}$ & -3.2 & -2.4 \\
\hline $\mathrm{Ag}^{+}$ & $1.0 \times 10^{-5}$ & 4.3 & 3.2 \\
\hline $\mathrm{Cd}^{2+}$ & $1.0 \times 10^{-5}$ & -3.9 & -2.9 \\
\hline $\mathrm{Co}^{2+}$ & $1.0 \times 10^{-5}$ & 3.7 & 2.7 \\
\hline $\mathrm{Ni}^{2+}$ & $1.0 \times 10^{-5}$ & 2.5 & 1.9 \\
\hline $\mathrm{Pb}^{2+}$ & $1.0 \times 10^{-5}$ & 3.8 & 2.8 \\
\hline $\mathrm{Cu}^{2+}$ & $1.0 \times 10^{-5}$ & -4.1 & -3.0 \\
\hline
\end{tabular}

a The concentration of $\mathrm{Hg}^{2+}$ was fixed at $2.0 \times 10^{-7} \mathrm{~mol} \mathrm{~L}^{-1}(\mathrm{pH} \mathrm{8.0})$.

b $F_{i}$ and $F_{i 0}$ are the fluorescence intensities of the sensing membrane contacting with $2.0 \times 10^{-7} \mathrm{~mol} \mathrm{~L}^{-1} \mathrm{Hg}^{2+}$ solution with and without the addition of the interferent.

Table 3

Determination of $\mathrm{Hg}^{2+}$ in different water samples.

\begin{tabular}{|c|c|c|c|}
\hline Sample & $\mathrm{Hg}^{2+}$ spiked $\left(\mathrm{mol} \mathrm{L}^{-1}\right)$ & $\mathrm{Hg}^{2+}$ founded $\left(\mathrm{mol} \mathrm{L}^{-1}\right)\left(\right.$ mean $^{\mathrm{a}} \pm$ S.D. $\left.{ }^{\mathrm{b}}\right)$ & Recovery (\%) \\
\hline \multicolumn{4}{|c|}{ Xiang river } \\
\hline 1 & $6.0 \times 10^{-8}$ & $(6.31 \pm 0.43) \times 10^{-8}$ & 105.2 \\
\hline 2 & $4.0 \times 10^{-7}$ & $(3.74 \pm 0.25) \times 10^{-7}$ & 93.5 \\
\hline 3 & $2.0 \times 10^{-6}$ & $(1.92 \pm 0.32) \times 10^{-6}$ & 96.0 \\
\hline \multicolumn{4}{|c|}{ Tap water } \\
\hline 1 & $8.0 \times 10^{-8}$ & $(7.79 \pm 0.29) \times 10^{-8}$ & 97.4 \\
\hline 2 & $4.0 \times 10^{-7}$ & $(4.11 \pm 0.34) \times 10^{-7}$ & 102.8 \\
\hline 3 & $1.0 \times 10^{-6}$ & $(0.95 \pm 0.21) \times 10^{-6}$ & 95.1 \\
\hline \multicolumn{4}{|c|}{ Waste water } \\
\hline 1 & $5.0 \times 10^{-8}$ & $(5.47 \pm 0.48) \times 10^{-8}$ & 109.4 \\
\hline 2 & $4.0 \times 10^{-7}$ & $(4.30 \pm 0.46) \times 10^{-7}$ & 107.5 \\
\hline 3 & $3.0 \times 10^{-6}$ & $(2.78 \pm 0.37) \times 10^{-6}$ & 92.7 \\
\hline
\end{tabular}

${ }^{\text {a }}$ Mean of three determinations.

b Standard deviation.

Table 2 revealed that most of the species tested caused no interference when existed in specified molar excesses.

\subsection{The response mechanism of the sensing membrane}

The sensing membrane described here belongs to the class of ionic-exchange system described previously [43]. The extraction of $\mathrm{Hg}^{2+}$ from the aqueous sample solution into membrane phase and its complexation by the lipophilic fluorescence indicator TDMAPP proceeded with the loss of two protons from the nitrogen atoms. This ionic-exchange process was determined by the electroneutrality in the organic membrane phase. TDMAPP immobilized in the PVC membrane acted not only as a selective host molecule for $\mathrm{Hg}^{2+}$, but also as a fluorescence transducer. The sensing mechanism involved the extraction of $\mathrm{Hg}^{2+}$ from aqueous sample solution to organic membrane phase and the formation of a metalloporphyrin complex between TDMAPP and $\mathrm{Hg}^{2+}$, which resulted in the fluorescence quenching of TDMAPP.

\subsection{Preliminary analytical application}

Recovery of spiked $\mathrm{Hg}^{2+}$ in different water samples was studied with the prepared optical sensor. Different water samples were simply filtered and the results showed that no $\mathrm{Hg}^{2+}$ existed. Thus, different concentrations of $\mathrm{Hg}^{2+}$ were respectively spiked in filtered water samples and then analyzed with the optical sensor. Results are shown in Table 3. One can see that the recovery study of spiked $\mathrm{Hg}^{2+}$ determined by the TDMAPP-based optical sensor exhibited satisfactory results.

\section{Conclusions}

Three porphyrin compounds were synthesized. Their fluorescence spectra and their response characteristics to $\mathrm{Hg}^{2+}$ were investigated. Among them, TDMAPP showed preferable fluorescence response to $\mathrm{Hg}^{2+}$. Thereby, a sensitive, fast and simple optical sensor for the determination of $\mathrm{Hg}^{2+}$ has been developed based on the fluorescence quenching of TDMAPP. The quenching of TDMAPP fluorescence was fast and the degree of the quenching was proportional to $\mathrm{Hg}^{2+}$ concentration. The sensing membrane containing TDMAPP reversibly responded to $\mathrm{Hg}^{2+}$ and showed extremely high selectivity to $\mathrm{Hg}^{2+}$ in the presence of some alkali, alkaline earth and heavy metal ions. The limit of detection for $\mathrm{Hg}^{2+}$ was $8.0 \times 10^{-9} \mathrm{~mol} \mathrm{~L}^{-1}$. This sensor has been used for the determination of $\mathrm{Hg}^{2+}$ in different water samples with satisfactory recovery.

\section{Acknowledgements}

This work was supported by "973" National Basic Research Program of China (No. 2007CB310500) and NSF (20775023, 20675028, 20775023) of China.

\section{References}

[1] R.C. Hughes, A.J. Rocco, M.A. Buttler, S.J. Martin, Science 354 (1991) 74

[2] J.M. Lehn, Supramolecular Chemistry, VCH, Verlagsgesellschaft, 1995.

[3] B. Valeur, I. Leray, Coordin. Chem. Rev. 205 (2003) 3.

[4] J. Janata, Anal. Chem. 64 (1999) 921A.

[5] P. Buhlmann, E. Pretsch, E. Bakker, Chem. Rev. 98 (1998) 1593.

[6] A.P. De Silva, N. Gunaratne, A.J.M. Huxley, C.P. McCoy, J.T. Rademacher, T.E. Rice, Chem. Rev. 97 (1997) 1515. 
[7] E. Bakker, P. Buhlmann, E. Pretsch, Chem. Rev. 97 (1997) 3083.

[8] R. Eugster, U.E. Spichiger, W. Simon, Anal. Chem. 65 (1993) 689.

[9] W.E. Morf, K. Seiler, B. Lehmann, C. Behringer, W. Simon, K. Harman, Pure Appl. Chem. 61 (1998) 1613.

[10] M. Biesaga, K. Pyrzynska, M. Trojanowicz, Talanta 51 (2000) 209.

[11] R.H. Yang, K.A. Li, K.M. Wang, F.L. Zhao, N. Li, F. Liu, Anal. Chem. 75 (2003) 612.

[12] J.P. Vernet, Heavy Metals in the Environment, Elsevier, New York, 1991.

[13] J. Frausto da Silva, R.J.P. Williams, The Biological Chemistry of the Elements, Clarendon Press, Oxford, 1993, p. 539.

[14] T. Tsubaki, K. Irukayama, Minamata Disease: Methylmercury Poisoning, Kodensha, Tokyo, 1977.

[15] X.J. Zhu, S.T. Fu, W.K. Wong, H.P. Guo, W.Y. Wong, Angew. Chem. Int. Ed. 45 (2006) 3150.

[16] Z. Fang, B. Liu, Tetrahedron Lett. 49 (2008) 2311

[17] C.K. Chiang, C.C. Huang, C.M. Liu, H.T. Chang, Anal. Chem. 80 (2008) 3716.

[18] M. Shamsipur, M. Hosseini, K. Alizadeh, N. Alizadeh, A. Yari, C. Caltagirone, V. Lippolis, Anal. Chim. Acta 533 (2005) 17.

[19] C.L. He, F.L. Ren, X.B. Zhang, Z.X. Han, Talanta 70 (2006) 364

[20] I. Cesarino, G. Marino, J.D. Matos, E.T.G. Cavalheiro, Talanta 75 (2008) 15.

[21] S.Y. Huan, C.X. Jiao, Q. Shen, J.H. Jiang, G.M. Zeng, G.H. Huang, G.L. Shen, R.Q. Yu, Electrochim. Acta 49 (2004) 4273.

[22] V.K. Gupta, A.K. Singh, A. Al Khayat, B. Gupta, Anal. Chim. Acta 590 (2007) 81.

[23] O. Ordeig, C.E. Banks, J. del Campo, F.X. Munoz, R.G. Compton, Electroanalysis 18 (2006) 573.
[24] M.H. Mashhadizadeh, M. Talakesh, M. Peste, A. Momeni, H. Hamidian, M. Majum, Electroanalysis 18 (2006) 2174.

[25] F. Kuralay, H. Ozyoruk, A. Yildiz, Enzyme Microb. Technol. 40 (2007) 1156.

[26] H. Dong, L. Lin, H. Zheng, G.X. Zhao, B.X. Ye, Electroanalysis 18 (2006) 1202.

[27] Y. Zhang, S.B. Adeloju, Talanta 74 (2008) 951.

[28] M. Ghaedi, M.R. Fathi, A. Shokrollahi, F. Shajarat, Anal. Lett. 39 (2006) 1171.

[29] B.C. Mondal, A.K. Das, Anal. Chim. Acta 477 (2003) 73.

[30] M.A.H. Hafez, I.M.M. Kenawy, M.A. Akl, R.R. Lashein, Talanta 53 (2001) 749.

[31] P.C. Rudner, A.G. de Torres, J.M.C. Pavon, F.S. Rojas, Talanta 46 (1998) 1095.

[32] S. Ichinoki, Y. Nagura, Y. Fujii, J. Liq. Chromatogr. Related Technol. 31 (2008) 1314.

[33] B. Vallant, R. Kadnar, W. Goessler, J. Anal. Atom. Spectrom. 22 (2007) 322.

[34] S. Ichinoki, S. Okada, Y. Fujii, J. Liq. Chromatogr. Related Technol. 28 (2005) 1751

[35] Y.T. Chang, S.J. Jiang, J. Anal. Atom. Spectrom. 23 (2008) 140.

[36] Z.F. Zhang, S.Y. Chen, H.M. Yu, M. Sun, W.Q. Liu, Anal. Chim. Acta 513 (2004) 417

[37] S.M. Williams, J.S. Brodbelt, A.P. Marchand, D. Cal, K. Mlinaric-Majerski, Anal. Chem. 74 (2002) 4423

[38] J.M. Liu, W.T. Chen, Q.H. Wang, L.D. Li, Talanta 62 (2004) 713.

[39] A.D. Alder, F.R. Longo, J.D. Finarelli, J. Goldmacher, J. Aaaour, L. Koresakoff, J. Org. Chem. 32 (1967) 476

[40] Y.Q. Liu, S.T. Han, J.Q. Zhou, H. Xie, Chem. Reagent 17 (1995) 252.

[41] M. Brulx, J. Elguero, W. Meutermans, J. Chem. Res. (S) (1992) 370.

[42] K. Seiler, W. Simon, Anal. Chim. Acta 266 (1992) 73.

[43] W.H. Chan, R.H. Yang, K.M. Wang, Anal. Chim. Acta 444 (2001) 261. 